\title{
Enhancing Motivation to Learn among Arab Pre- service Teachers in Arab and Mixed Colleges
}

\author{
By Basma Jarjoura*
}

\begin{abstract}
This ongoing research attempts to get insights on the Arab pre-service teachers' motivation to learn from a self-determination theory (SDT) perspective, and shed light on what is happening within the confines of the Arab colleges and mixed colleges pedagogically and socially. The theoretical model consists of two levels: a a micro level in which the effect of each of the following variables on students' autonomous and controlled motivation was examined in each college type separately: sociodemographic characteristics, Hebrew fluency, students' choices of college type and Special Education Department (CCSE), autonomy support, relatedness, competence, program evaluation and attitudes toward teaching, and $b$. a macro level in which the effect of the college type on the relationship between all the above variables and the two types of motivation was examined. The present paper combines both the micro and macro-levels in order to provide a thorough analysis the determinants of students' motivation and examine issues that have not received enough attention. For this purpose, quantitative approach was used. Finally, the present study's intermediate results could assist in designing effective policy guidelines to the pedagogical supervisors and policy makers.
\end{abstract}

Keywords: Arab colleges, Arab minority, autonomous motivation, mixed colleges, self-determination theory (SDT)

\section{Introduction}

\section{The Arab Minority in Israel}

The Arab minority in Israel differs from the Jewish majority in religion, language, culture, history, nationality, areas of residence and lifestyle. The Arab in Israel maintained their language and culture, as $90 \%$ of them live in geographically separate cities and villages. Those who live in mixed cities in Israel are generally located in separate neighborhoods (Haidar, 2005).

The Arab society is characterized as collective, traditional, patriarchal and authoritarian (Dwairy, 1998; 2001). Men are the most important source of authority in the family and play the role of the key decision makers in the family (Al-Haj, 2002). A collective society is a traditional and homogeneous society, characterized by interdependent relationships between people. The extended family is the core of the Arab social group (Hofstede \& McCare, 2004) shaping the life of the individual, and directing his behavior and values through fixed norms. These norms emphasize the hierarchy and social harmony that is expressed under the control of men and their superiority on women.

* Lecturer, Oranim Academic College, Israel. 
However, it should be noted here that these characteristics are changing in the Arab society (Abu-Baker \& Dwairy, 2003; Al-Haj, 1989; Haj-Yahia, Bargal, \& Guterman, 2000).

The Arab family provides security and support in times of personal, social or family distress. Thus, the personal successes and failures of the family's members are not considered as their strictly personal affairs but they are regarded as the whole family's concerns. The Arab family plays a protective role, shielding its members against "external risks" and usually provides for their needs. Thus, an individual's self-image, self-esteem, excellence and success, confidence and identity are traits valued on the grounds of their connections with the family. Threats of a disruption in the provision of family support could permanently damage an individual's self-confidence, cause him or her anxiety and harm the ability to cope with the demands of life (HajYahia, 1995).

Structural and cultural factors embedded in Israeli society contributed to the process of individualization of the Palestinian society in Israel. Nowadays, the Palestinian society in Israel is in a continuous process of reshaping its values and searching for modern as well as original ways of action and expression trends. Palestinians in Israel are struggling and trying to define their own identity and nationality, goals, aspirations and ways of action. The transition process is reflected in various fields such as the economy, education and culture as well as in the status of women in both the societal and family level (Haj-Yahia, 1995).

In the 1950s Arabs were a traditional society and largely illiterate. Nowadays, there is still a considerable gap between them and the Jews in terms of social stratification. In this context, their options are more limited than those available to the Jews because of the security situation as well as the phenomenon of ethnic discrimination constituting a major problem in Israel (Ben-Raphael, 2002; Diab \& Daas, 2013).

\section{The Hebrew Language among Arabs}

Being a minority, the Israeli-Arab population in Israel learns Hebrew as second language (L2) since this is the official language of the dominant group (Abu-Rabia, 1999). Spolsky and Shohamy (1999) argued that the main problem in the education of Israeli -Arab is the teaching of the Hebrew language. Due to the fact that it is taught as a second language and not as a foreign language -despite the gaps between the citizens in cities and villages in the level of exposure to Hebrew in the course of their daily routines- many students do not reach the level required to study in the university. Consequently, the language constitutes a barrier to higher education. The Hebrew language is a major obstacle. Although Arab students study Hebrew in Arab schools, there is almost no use of the language outside the class so there is an immediate difficulty in excelling in speaking, understanding, reading and academic writing (Shavev, Benshtain, Ston, \& Poden, 2013).

\section{The Arab Students}


In Israel there are two separate educational systems; Jewish schools and Arab schools. The separation between the two systems could be attributed to several reasons. The major one among them is the concentration of the Arab citizens in the Arab areas where Arabs can get education in an appropriate environment consistent with their lifestyle, enabling them to maintain their cultural, religious and linguistic traditions (Al-Haj, 1996). In contrast, higher education provided in the context of universities has mixed characteristics -Jew and Arab students sit side by side in class with the Jews being, expectedly, the majority (Peleg \& Raslan, 2003).

Israeli-Arab citizens who wish to obtain the teaching certificate can choose between enrolling in university for an academic preparation for a teaching career or in teacher training colleges. Some of those students choose to join the Arab colleges, but many others choose to join official public academic colleges (sometimes called Hebrew or Jewish colleges). Two options are available in academic colleges to Arab students (1) joining the course of public education; (2) enrolling in private separate divisions of multiple names such as: Bedouin and Arabs education tracks or institute for the preparation of Arab teachers (Daas, 2013, p. 132; Raingold \& Paul, 2013, p. 275). Most of the Arabs attending Jewish colleges choose to attend Arab programs (Agbaria, 2010).

\section{Theoretical Conceptualization}

Self Determination Theory (STD) identifies the core principles underlying sustainable motivation (Deci and Ryan 1985; Ryan and Deci, 2000). It is one of the most comprehensive and empirically supported theories of motivation available today (Schunk, Pintrich, \& Meece, 2008, p. 248). In fact, this theoretical perspective has generated a large amount of research in the field of education (Deci, Vallerand, Pelletier, \& Ryan, 1991). Recently, it has been used to better understand important educational outcomes such as dropout behavior (Vallerand \& Bissonnette, 1992; Vallerand, Fortier, \& Guay, 1997), personal adjustment in the school context (Connell \& Wellborn, 1990; Skinner, Wellborn, \& Connell, 1990), as well as learning and school performance (Fortier, Vallerand, \& Guay, 1995; Grolnick, Ryan, \& Deci, 1991). Thus it will contribute to the provision of thorough and well-grounded answers to the research questions addressed in the present study.

SDT is mainly interested in promoting students' curiosity in learning, motivating them to grow their strengths and competencies and improving their level of wellbeing (Ryan \& Weinstein, 2009). People are considered as having inherent and deeply evolved propensities to receive knowledge and develop new skills. However SDT argues that these natural propensities can be either supported or diluted within various social contexts. School and classroom strategies, including grades, evaluations, rewards and external pressures, are thus of particular interest within SDT as they influence the students' potential 
to learn and develop.

SDT distinguishes between intrinsic motivation and extrinsic motivation (Deci \& Ryan, 1985; Ryan \& Deci, 2000; Ryan \& Weinstein, 2009). Extrinsic Motivation is defined as the situation where a person does an action in order to fulfill his/her society expectations, avoid sanctions or comply with external control. In other words, it describes an activity done for its instrumental value. On the other hand, Intrinsic Motivation is the term describing the cases where individuals are involved in certain activities because of their personal interests and pursuit of satisfaction (Ryan \& Deci, 2000).

Ryan and Deci (2009) did not settle with a simple dichotomous definition of extrinsic and intrinsic motivation. Instead, they defined a continuous process in their attempt to analyze internalization. According to their new definition, "internalization is a process of transferring the regulation of behavior from outside to inside the individual". This process is necessary for the regulation of extrinsically motivated behaviors, being consistent with the process of transformation of social norms into personal values (Deci \& Ryan, 1985). The process of moving from external to internal regulation involves several levels defined according to Ryan and Deci (2009)

- external-regulation: factors and circumstances outside the individual which affect their motivation;

- introjected-internal regulation: where the individual feels that he/she should or has to behave in a certain way;

- identified-internal regulation: which is based on the utility that the individual expects to gain from a specific course of action (e.g. as given by the authors: studying hard to get grades to get into college);

- integrated-regulation: based on what the individual considers valuable and important.

Even though the integrated level is self-determined, it still does not reflect intrinsically motivated behavior. Intrinsic motivation only occurs when the individual autonomously controls his or her behavior, which may not be the case even at the integrated level of regulation (Wigfield, Cambria \& Eccles, 2012). Pre-service teachers with intrinsic motivation tend to engage in teaching because they enjoy it and they get satisfaction from performing teaching related actions. Pre-service teachers with identified motivation are considered to be more autonomous than teachers with external or introjected motivation but they are not as fully autonomous as those with intrinsic motivation (Kim \& Cho, 2014).

\section{Autonomous and Controlled Motivation}

The multidimensional view of SDT motivation distinguishes the quantity, amount, or strength of motivation from the quality or type of motivation. This conceptualization of the different aspects of motivation is a quite exceptional 
feature of the theory. Currently, popular motivation theories, including selfefficacy theory (Bandura, 1989) and expectancy-value theory (Eccles \& Wigfield, 2002) consider motivation to be a unitary, quantitative theoretical construction and propose that a higher amount of motivation should lead to more optimal outcomes. As opposed to the predictions and evaluations of the above theoretical scheme, SDT suggests that higher levels of motivation do not necessarily lead to more favorable outcomes; the quality of motivation determines the outcomes of one's motivation, for example if the motivation is controlled rather than autonomous in nature, then the expected outcome could be of poor quality (Ryan \& Deci, 2000).

Autonomous regulation involves experiencing a sense of full volition and freedom of choice. Autonomous regulation is when a course of action is felt to be personally important and compatible with the individual's core values. Such a behavior is expected to emerge from the individual's true sense of self, thus being considered as self-determined. In contrast, controlled regulation involves a person feeling pressured or coerced by an external force. When being under control, a person responds to external stimuli on the basis of his or her rigid beliefs that he or she should act as expected. In this sense, individuals feel that they are obliged to do so in order to feel worthy. They could also behave in a certain way because of their expectations of future threats or rewards from external agents (Williams et al., 2002).

Within SDT, extrinsic motives are further differentiated into those that are controlled versus those that are more autonomous. SDT-based research has always demonstrated that more autonomous forms of motivation are related with a mass of positive outcomes from better academic performance, creativity, and persistence, to enhanced learner wellbeing. SDT suggests that within the social context, autonomous motives, as well as the energy and engagement that they induce, are supported by widely accepted notions regarding autonomy, competence, and relatedness. In this view, the effects of classroom events such as examinations, teacher feedback, or the introduction of a new curriculum on students' motivation are determined by the functional importance, or meaning of these events with respect to these three basic needs (Ryan \& Deci, 2000).

\section{Human Needs}

The main tenets of SDT focus on human beings having three inherent psychological needs: relatedness, competence and autonomy (Deci \& Ryan, $1985 ; 2000 ; 2008)$. Relatedness refers to the need to feel related to others and have the reassuring sense of belonging to a social group. In the case of the teacher-student relationship, supporting relatedness means providing acceptance, respect, and a feel of caring to the students (Deci \& Ryan, 1985). Competence is the need to feel that one is effective in performing the requisite actions. Competence and self-efficacy are closely similar while it is clear that many students manage or fail to develop self-efficacy within a given educational setting. Autonomy refers to the need to express one's authentic self 
and to feel that this self is the source of action. Autonomy is not synonymous to independence or total freedom, but rather it refers to an internal acceptance of, and engagement with, one's motivated behavior. Supporting autonomy means taking the student's perspective under consideration by providing a set of alternatives, encouraging them to make a free choice, or being able to providing the students with a meaningful rationale when choosing is not an option (Deci \& Ryan, 1985). According to SDT these three needs, when satisfied, promote psychological well-being (Filak \& Sheldon, 2003). Essentially, satisfaction of autonomy and competence needs is necessary in order to maintain intrinsic motivation. This view is contrary to what is theorized by self-efficacy theory (Bandura, 1989) which rejects functional significance of autonomy. Thus, students who feel competent, but not autonomous, will not maintain intrinsic motivation for learning. Many experimental studies have supported the SDT claim that both autonomy and competence are required for intrinsic motivation to be preserved (Niemiec \& Ryan, 2009).

Several studies have analyzed the relationship between these three human needs and types of motivation (Connell \& Wellborn, 1990; Deci et al., 1991; Deci \& Ryan, 2000; Niemiec \& Ryan, 2009; Ryan \& Deci, 2000). If those three needs are satisfied, an individual's motivation, growth and well-being will be enhanced. In contrast, if the three needs are not supported, motivation, growth and well-being will be diminished (Deci \& Ryan, 2000). In other words, the satisfaction of these psychological needs will result in the formation of a complex set of motives, ranging from intrinsic to extrinsic (Niemiec \& Ryan, 2009).

\section{The Current Study}

\section{The Research Problem}

College student motivation to learn is a consistent problem at all levels of post-secondary education. Faculty and staff at colleges, in private and public universities all sigh on the lack of student motivation to learn (Pintrich \& Zusho, 2007). Students seem to lack the desire to study or to try very hard, postponing their studying to the last minute before an examination or starting to write a paper the day before it is due. Neither they are organized enough to be able to plan their work in an efficient way, nor they learn how to achieve high quality performance. Late arrival to class, absence from lessons, boredom, non-satisfaction and complaints, low grades and lack of persistence, all being common elements of their behaviour, reflect their lack of desire to study. Furthermore, nearly all of these students start teaching in Arab schools if they find a job opportunity (due to excess of Arab graduates from colleges of education). During the first years of a teacher's school entry, his or her role is particularly difficult due to the existing organization and education related difficulties in Arab schools. In the context of the difficult and complex reality 
of Arab schools, new teachers often struggle for survival in the education system, dealing with feelings of frustration, helplessness, disappointment and loneliness. Choosing the teaching profession as the only employment opportunity, accompanied by the negative feelings discussed above, increases their frustration, having strong implications for their performance and contribution in the school system (Agbaria, 2009; Ilaiyan, Zedan, \& Torin, 2007).

\section{The Research Gap}

In spite of the growing public interest in evaluating teacher training institutions in Israel, the performance of Arab students in teacher training programs remains understudied compared to Jewish students. Arab students in Arab and mixed colleges go through different socialization process in various levels: academically, pedagogically, psychosocially and linguistically (Agbaria, 2010).

It is considered essential to improve student's achievement for the purpose of nurturing future teachers with strong sense of responsibility and commitment to the mission of teaching. The state's best energies should be invested in preparing future educators having the qualities that will provide students with better chances for development and progress. Thus, the motive of the present study stems from both pedagogical concerns and academic interests.

\section{Research Goals}

The purpose of this study is to examine the influence of the social and pedagogical learning context on developing motivation among Arab preservice teachers in Special Education Departments. This research attempts to gain insight into the Arab pre-service teachers' motivation to learn from a selfdetermination theory (SDT) (Deci \& Ryan, 1985) perspective, and shed light on the learning procedure taking place within the confines of the Arab colleges and mixed colleges.

\section{Research Predictor (Independent) Variables}

- Student background characteristic: socio-demographic: gender, age, current marital status, current household income, permanent residence, father's education, mother's education, religion, religiosity, current study year at the department, work.

- Level of Hebrew fluency.

- Student choices (CCSE): Choosing the College (cultural characteristics of the college - Arab vs. mixed college), and choosing the Department of Special Education. 
- The three psychological needs: Autonomy support, competence, and relatedness. Previous research has provided evidence in favor of the positive effects of autonomy and self-determination on school children and on differentially abled learners (Deci et al., 1991; Skinner \& Belmont, 1993). The suggested research presented here will attempt to further support hypothesis of the benefits entailed in fostering autonomy, competence and relatedness among the ethnic group under analysis within the academic setting.

- Program evaluation: The students' evaluation of the Special Education program they attend.

- Attitudes toward the teaching profession: The students' attitudes toward the teaching profession.

\section{Research Outcome Variables}

Two dependent variables: autonomous motivation and controlled motivation. The level and type (autonomous versus controlled) of motivation were tested.

\section{Main Research Question}

The influence of the social and pedagogical learning context on developing motivation to learn among Arab pre-service teachers for Special Education in two different types of teacher training colleges: Arab colleges and mixed colleges.

\section{Sub Questions that Stem from the above Mentioned Main Research Question}

1. Do the autonomous and controlled types of motivation differ in quantity and quality between students from mixed colleges and those from Arab colleges?

2. Do the variables of interest significantly explain the two types of motivation?

3. Does the college type affect the relationship between those variables and the two types of motivation (moderation)?

\section{Research Hypotheses}

1. The students in the Arab colleges will have higher levels of motivation and higher levels of autonomous motivation than controlled. The minority students face more difficulties at the universities where Israeli students are the majority. In addition, their achievements are lower than the others (Ying et al., 2001). It seems that Arab students face many challenges by the time they enter university. As a result, they experience more pressure than Jewish students (Zeidner, 1992). 
2. Different variables of interest will significantly explain the evolution of students' motivation.

3. College type will be a significant moderator of the manifestation of both types of motivation.

\section{Theoretical Model}

Figure 1 illustrates the theoretical model that summarizes the above hypotheses.

Figure 1. Theoretical Model

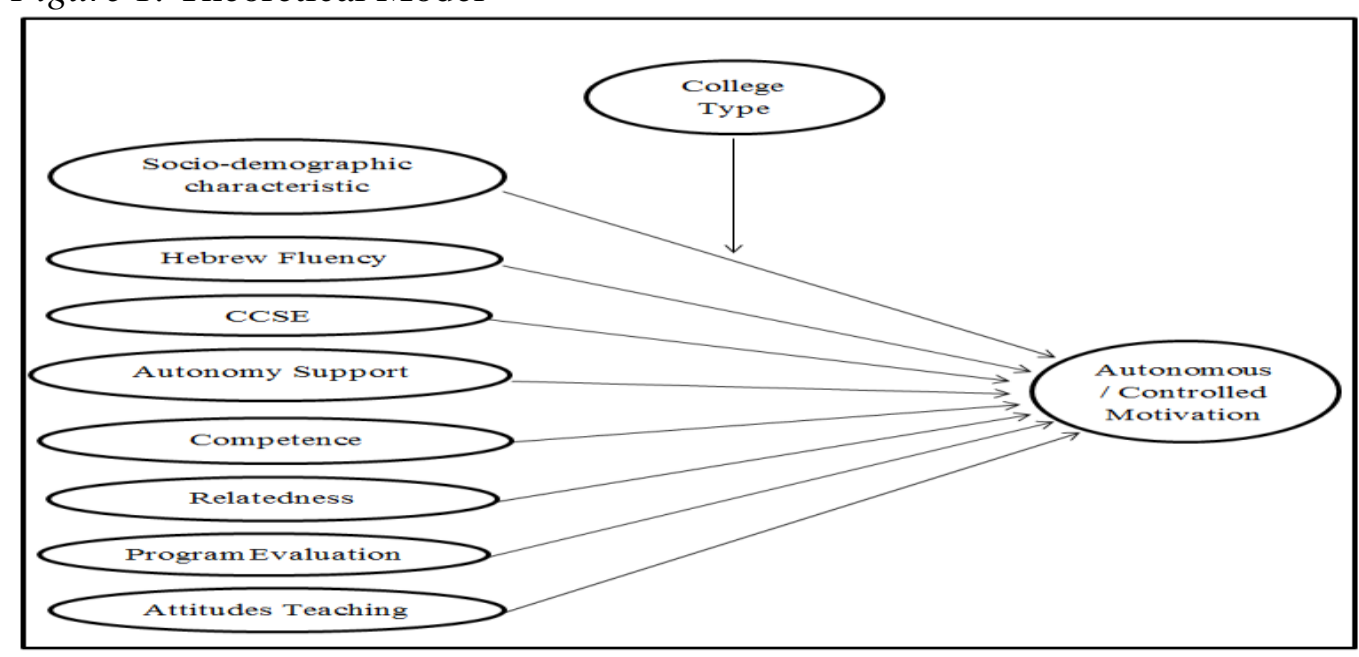

\section{Theoretical Model Proposed}

The proposed theoretical model consists of two levels (a) a micro level in which the effect of each of the variables of interest on students' autonomous and controlled motivation is examined; (b) a macro level, in which the influence of the college type (as a moderator) on the relationship between all the above variables and motivation, is analyzed.

\section{Participants}

353 Arab pre-service teachers were included in this study attending courses in the four largest teacher training colleges in the center of Israel: two Arab colleges and two Arab sections in mixed colleges. 92.6\% of the respondents are females and the rest $7.4 \%$ are males. Special Education Departments served as a baseline for comparison.

\section{Methods of Data Collection}

In this research a mixed method (qualitative and quantitative) was used: interviews of focus groups and closed questionnaires. In this article the 
quantitative part of the research is presented.

\section{Methods of Data Analysis}

Quantitative Analysis of the results was done using the multiple hierarchical regression model.

\section{Description of the Colleges}

In the context of the present study, the learning experience is not based solely on the students' involvement in the classroom but on their general experience as students at a specific college constituting a holistic learning environment with specified rules and relations, as well as various learning processes. The main assumption of this study is that this holistic experience affects students' motivation to learn. For this purpose, the students' motivation to learn is analyzed in two different types of teacher training colleges, representing different holistic learning environments, on a comparative basis: two Arab and two mixed colleges.

Similar colleges of each type were selected in terms of various parameters. The parameters of each college were examined prior to the classification in order to ensure there exists the similarity in their characteristics necessary to make the categorization meaningful and valid.

\section{Descriptive Statistics of the Two College Types}

The sample consists of 353 (26 male and 327 female) pre-service teachers for Special Education both in Arab and mixed colleges. The majority of participants were aged between 21 and 25 years (63.4\%). An alpha level of 0.05 was used for all statistical tests.

After checking for missing data and outliers, the data's normality, linearity and homoscedasticity properties were tested and it was found to fit the requirements for parametric data analysis. Therefore, proceeded to the hypothesis tests. Table 1 presents descriptive statistics for the predictor variables.

\section{Relationship between LSR and Socio-Demographic (Ordinal Variables)}

Spearman correlation tests were conducted among the following categorical variables: age, income, fathers' education, mothers' education, religiosity and both types of LSR: autonomous regulation and controlled regulation. The results of the correlations in Table 2 show that age and religiosity are positively and significantly correlated $\left(r_{s}=0.144, n=348\right.$, $\mathrm{p}=0.007$ ), meaning that older students are more religious. A significant positive correlation was also found between family income and fathers' education, $\left(\mathrm{r}_{\mathrm{s}}=0.266, \mathrm{n}=343, \mathrm{p}<0.0001\right)$ as well as between family income and mothers' education $\left(\mathrm{r}_{\mathrm{s}}=0.284, \mathrm{n}=343, \mathrm{p}<0.0001\right)$, indicating that parents with higher 
levels of education are expected to earn higher income. Significant positive correlation was also found between mothers' education level and fathers' education level $\left(\mathrm{r}_{\mathrm{s}}=0.489, \mathrm{n}=352, \mathrm{p}<0.0001\right)$. Student autonomous regulation was found to be significantly and negatively correlated to the parents' education level, meaning that it is more probably for students coming from a low education background to have higher levels of autonomous regulation (Correlation with the fathers' education: $r_{s}=-0.171, n=352, p=0.001$; Correlation with the mothers' education: $\mathrm{r}_{\mathrm{s}}=-0.114, \mathrm{n}=352, \mathrm{p}=0.032$ ). Similarly, students with parents' of lower skills and education demonstrate higher levels of controlled regulation (Correlation with the fathers' education: $r_{s}=-0.105, n=349, p=0.049$; Correlation with the mothers' education: $r_{s}=0.337$, $\mathrm{n}=353, \mathrm{p}<0.0001)$. Religiosity was also found to be significantly and negatively correlated to students' autonomous regulation $\left(r_{s}=-0.138, n=349\right.$, $\mathrm{p}=0.010$ ). Relationships among the rest mentioned variables were not found to be of statistical significance.

Table 1. Descriptive Statistics: Arab and Mixed Colleges

\begin{tabular}{|c|c|c|c|c|c|c|}
\hline \multicolumn{2}{|c|}{ College Type } & $\mathbf{N}$ & Min & Max & $\mathbf{M}$ & SD \\
\hline \multirow{10}{*}{$\begin{array}{l}\text { Arab } \\
\text { Colleges }\end{array}$} & Program Evaluation & 177 & 1.73 & 5.00 & 3.6754 & 0.60688 \\
\hline & Attitudes Teaching & 177 & 2.80 & 5.00 & 4.2311 & 0.48920 \\
\hline & Hebrew Fluency & 177 & 2.00 & 5.00 & 3.9732 & 0.75353 \\
\hline & $C C S E$ & 177 & 1.00 & 5.00 & 3.9054 & 0.82220 \\
\hline & Autonomy Support & 177 & 1.00 & 5.00 & 3.1704 & 0.75146 \\
\hline & Competence & 177 & 0.00 & 5.00 & 4.3432 & 0.63776 \\
\hline & Relatedness & 177 & 0.00 & 5.00 & 3.8425 & 0.75390 \\
\hline & LSR Autonomous M. & 177 & 2.00 & 5.00 & 4.1006 & 0.60080 \\
\hline & LSR Controlled M. & 177 & 1.57 & 4.71 & 3.2478 & 0.67407 \\
\hline & Valid N (list wise) & 177 & & & & \\
\hline \multirow{10}{*}{$\begin{array}{l}\text { Mixed } \\
\text { Colleges }\end{array}$} & Program Evaluation & 176 & 1.00 & 5.00 & 3.5124 & 0.73908 \\
\hline & Attitudes Teaching & 175 & 2.30 & 5.00 & 4.1634 & 0.57638 \\
\hline & Hebrew Fluency & 176 & 1.00 & 5.00 & 3.9474 & 1.08549 \\
\hline & $C C S E$ & 176 & 0.25 & 5.00 & 3.7898 & 0.98299 \\
\hline & Autonomy Support & 176 & 1.33 & 5.00 & 3.2964 & 0.78218 \\
\hline & Competence & 176 & 0.00 & 5.00 & 4.2045 & 0.64536 \\
\hline & Relatedness & 176 & 0.00 & 5.00 & 3.7734 & 0.70905 \\
\hline & LSR Autonomous M. & 176 & 0.00 & 5.00 & 3.8670 & 0.68172 \\
\hline & LSR Controlled M. & 176 & 0.00 & 4.71 & 3.0771 & 0.69498 \\
\hline & Valid N (list wise) & 175 & & & & \\
\hline
\end{tabular}

Source: Author's estimations. 
Table 2. Correlations between Dependent Variables and Socio-Demographic Variables

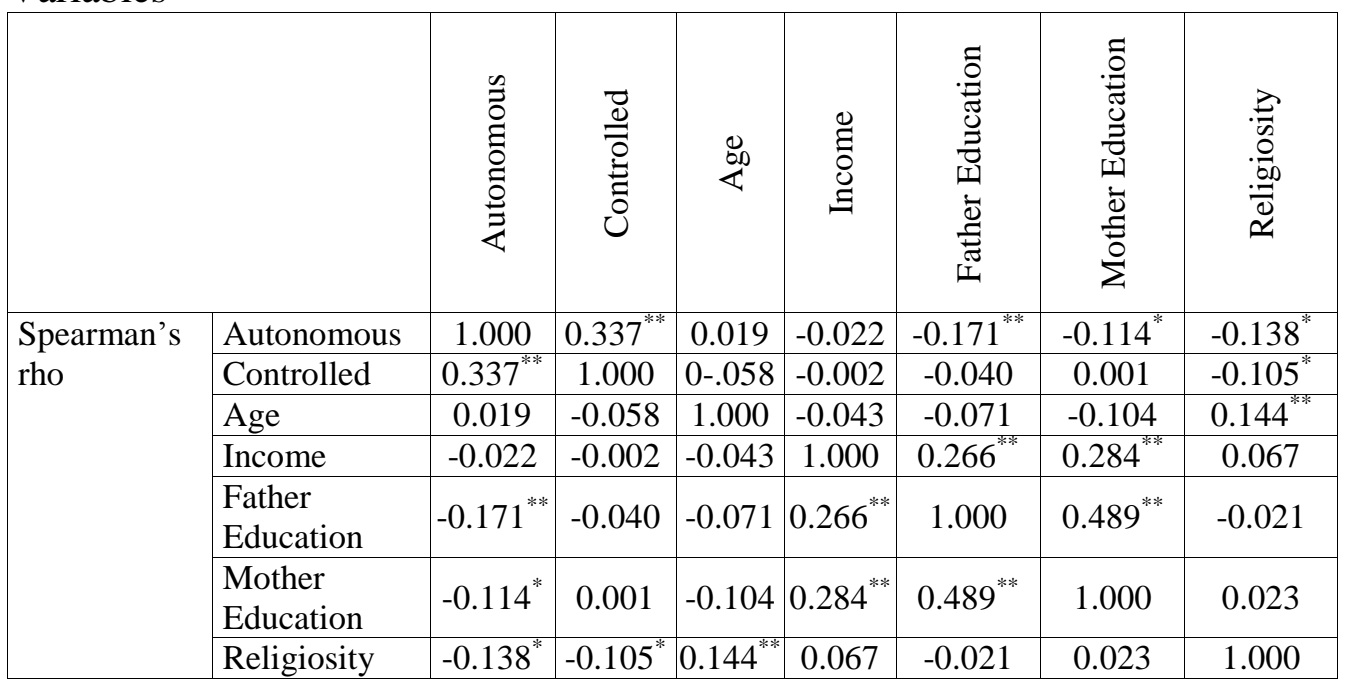

** Correlation is significant at the 0.01 level (2-tailed).

* Correlation is significant at the 0.05 level (2-tailed).

Source: Author's estimations.

\section{Group Mean Differences in both Types of Motivation by College Type}

SDT focuses not only on the quantity of motivation but also on its quality (Deci \& Ryan, 1985). The above aspect of this theoretical discourse translates into the first research question: Do the autonomous and controlled types of motivation differ between students from mixed colleges and those from Arab colleges?

Hypothesis: The students in the Arab colleges will have higher levels of motivation and more autonomous motivation than controlled.

An independent t-test and analysis of variance (ANOVA) were performed to examine whether there were significant group mean differences between the two types of motivation by college category. The results of the t-test revealed that there exists a significant correlation between college type and autonomous motivation $\left(\mathrm{t}_{(351)}=3.415, \mathrm{p}=0.001\right)$. Autonomous motivation was found to be higher in Arab colleges $(\mathrm{M}=4.1006, \mathrm{SD}=0.60080)$ than in mixed colleges $(\mathrm{M}=3.8670, \mathrm{SD}=0.68172)$.

A significant correlation was also found between college type and controlled motivation $\left(\mathrm{t}_{(351)}=2.342, \mathrm{p}=0.020\right)$. Controlled motivation $(\mathrm{M}=3.2478, \mathrm{SD}=0.67407)$ was found to be higher in Arab colleges than in mixed colleges $(M=3.0771, S D=0.69498)$. These results are partly consistent with the research hypothesis according to which students in the Arab colleges will have higher levels of motivation and more autonomous motivation than controlled (Table 3). 
Table 3. Independent Samples Test

\begin{tabular}{|c|c|c|c|c|c|c|c|c|c|c|}
\hline \multicolumn{11}{|c|}{ Independent Samples Test } \\
\hline & & \multicolumn{2}{|c|}{\begin{tabular}{|c|} 
Levene's test for \\
Equality of \\
Variances
\end{tabular}} & \multicolumn{7}{|c|}{ t-test for Equality of Means } \\
\hline & & \multirow[t]{2}{*}{$F$} & \multirow[t]{2}{*}{ Sig. } & \multirow[t]{2}{*}{$T$} & \multirow[t]{2}{*}{$D f$} & \multirow[t]{2}{*}{$\begin{array}{c}\text { Sig. } \\
\text { (2-tailed) }\end{array}$} & \multirow[t]{2}{*}{\begin{tabular}{|c|} 
Mean \\
Difference
\end{tabular}} & \multirow[t]{2}{*}{$\begin{array}{l}\text { Std. Error } \\
\text { Difference }\end{array}$} & \multicolumn{2}{|c|}{$\begin{array}{l}\text { 95\% Confidence } \\
\text { Interval of the } \\
\text { Difference }\end{array}$} \\
\hline & & & & & & & & & Lower & Upper \\
\hline \multirow{2}{*}{$\begin{array}{l}\mathscr{O} \\
\stackrel{\Xi}{\Xi} \\
\stackrel{\Xi}{\Xi} \\
\stackrel{\Xi}{\Xi}\end{array}$} & $\begin{array}{c}\text { Equal } \\
\text { variances } \\
\text { assumed }\end{array}$ & 1.351 & 0.246 & 3.415 & 351 & 0.001 & 0.233 & 0.068 & 0.099 & 0.368 \\
\hline & $\begin{array}{c}\text { Equal } \\
\text { variances } \\
\text { not } \\
\text { assumed }\end{array}$ & & & 3.414 & 345.05 & 0.001 & 0.233 & 0.068 & 0.098 & 0.368 \\
\hline \multirow{2}{*}{ 己 } & $\begin{array}{c}\text { Equal } \\
\text { variances } \\
\text { assumed }\end{array}$ & 0.094 & 0.760 & 2.342 & 351 & 0.020 & 0.170 & 0.072 & 0.027 & 0.313 \\
\hline & $\begin{array}{c}\text { Equal } \\
\text { variances } \\
\text { not } \\
\text { assumed } \\
\end{array}$ & & & 2.342 & 350.54 & 0.020 & 0.170 & 0.072 & 0.027 & 0.314 \\
\hline
\end{tabular}

Source: Author's estimations.

\section{Summary of Hierarchical Regression Analysis for Variables Predicting Autonomous Motivation ( $\mathbf{N = 3 5 3 )}$}

Second research question: Do the variables of interest significantly explain the two types of motivation?

Hypothesis: Different variables of interest will significantly explain the two types of motivation. According to SDT (Deci \& Ryan, 1985; 2000) the three psychological needs will significantly explain the autonomous motivation.

The study applied hierarchical regression analysis to examination results in search for the best predictors among the variables of interest in predicting students' motivation (LSR-autonomous and controlled). The variables of interest are: Hebrew fluency, CCSE, autonomy support, competence, relatedness, program evaluation and attitudes towards teaching. Among those, religion and residence served as controls for the autonomous motivation regression while religion was included in the model of controlled motivation.

The categorical religion variable (with the values 1 for Muslim; 2 for Christian and 3 for Druze) was collapsed into a dummy variable for each category in order to be included in the hierarchical regression. The same technique was implemented in the case of the region of residence variable (with the values 1 Arabic city; 2 mixed city; 3 Arabic village).

A hierarchical regression was conducted to determine the best predictors of autonomous motivation among the independent variables. Table 4 presented the statistics of a 3-step hierarchical regression, including the effect of the college type as a moderator. In step 1 (model 1) the socio-demographic variables were included but none of them was significant. Only religion and 
region of residence were chosen as controls in order to account for the differences in motivation attributed to religion and area of residence. Model 1 is significant $F(6,346)=5.089, p<0.0001$. Neither religion nor residence were significant predictors in the first step but they contributed to the improvement of the model's explanatory power by increasing $\mathrm{R}^{2}$ by 0.081

Then, the following independent variables: Hebrew fluency, CCSE, autonomy support, competence, relatedness and program evaluation were added at the second step of the hierarchical analysis (model 2). Model 2 is also significant according to the following statistics: $F(12,340)=22.284, p<0.0001$, $\mathrm{R}^{2}$ change $=0.359$, and adjusted $\mathrm{R}^{2}=0.420$. Adding these variables in the second step resulted in a more robust model. From the set of the independent variables, CCSE, autonomy support, competence, relatedness and program evaluation were found to be statistically significant. CCSE was found to be the strongest predictor $(\beta=0.258, \mathrm{p}<0.0001)$, followed by competence $(\beta=0.221, \mathrm{p}<0.0001)$, autonomy support $(\beta=0.198, \mathrm{p}<0.0001)$, relatedness $(\beta=0.184, \mathrm{p}<0.0001)$ and finally program evaluation $(\beta=0.129, \mathrm{p}=0.003)$. This implies that higher values of the five motivational predictors induce higher levels of autonomous motivation. However, Hebrew fluency was not found to be a significant factor in predicting autonomous motivation. Attitudes towards teaching and program evaluation were significantly correlated $\left(r_{p}=0.433, p<0.001\right)$, so they could not be both included in the model. Therefore, the measure of the attitudes towards teaching was not included in the model. Consequently, the validation of the hypothesis did not receive full empirical support.

Third research question: Does college type affect the relationship between the variables of interest and the two types of motivation (moderation)?

Third question hypothesis: College type will be a significant moderating factor.

Table 4. Model Summary

\begin{tabular}{|c|c|c|c|c|c|c|c|c|c|c|}
\hline \multirow[t]{2}{*}{ Model } & \multirow[t]{2}{*}{$\mathbf{R}$} & \multirow[t]{2}{*}{$\mathbf{R}^{2}$} & \multirow[t]{2}{*}{ Adj. $\mathbf{R}^{2}$} & \multirow{2}{*}{$\begin{array}{l}\text { Std. Error of } \\
\text { the Estimate }\end{array}$} & \multicolumn{5}{|c|}{ Change Statistics } & \multirow{2}{*}{$\begin{array}{l}\text { Durbin- } \\
\text { Watson }\end{array}$} \\
\hline & & & & & $\begin{array}{c}R^{2} \\
\text { Change }\end{array}$ & \begin{tabular}{|c|}
$F$ \\
Change
\end{tabular} & $d f 1$ & $d f 2$ & \begin{tabular}{|c|} 
Sig. $F$ \\
Change \\
\end{tabular} & \\
\hline 1 & $0.285^{\mathrm{a}}$ & \begin{tabular}{|l|}
0.081 \\
\end{tabular} & 0.065 & 0.63047 & 0.081 & 5.089 & 6 & 346 & 0.000 & \\
\hline 2 & $0.664^{\mathrm{b}}$ & 0.440 & 0.420 & 0.49640 & 0.359 & 36.357 & 6 & 340 & 0.000 & \\
\hline 3 & $0.691^{\mathrm{c}}$ & 0.478 & 0.450 & 0.48380 & 0.037 & 3.991 & 6 & 334 & 0.001 & 1.866 \\
\hline
\end{tabular}

Source: Author's estimations.

In the third step (model 3) the interactions between college type and the independent variables were added. Model 3 with the interactions is also significant: $\mathrm{F}(18,334)=16.970, \mathrm{p}<0.0001, \mathrm{R}^{2}$ change $=0.037$, adjusted $\mathrm{R}^{2}=0.450$ (Table 4). As in the second step of our analysis, the addition of the interaction terms improved the models' ability to explain the variance in the independent variable. Thus the third model explained $45 \%$ of the variance in autonomous motivation. The following interaction terms were found to be significant: college type and competence $(\beta=0.841, \mathrm{p}=0.006)$ followed by college type and relatedness $(\beta=0.564, p=0.016)$, and finally college type and program evaluation $(\beta=0.584, p=0.013)$. From the significant interactions with college type two were positive except with program evaluation. These results imply that college type affects the relationship between the independent variables and 
autonomous motivation. While the interactions of college type with competence and relatedness are positive, indicating that those two elements induce motivation in both types of colleges, the interaction with program evaluation is negatively correlated with autonomous motivation.

Table 5. Model Estimation Results of Autonomous Motivation

\begin{tabular}{|c|c|c|c|c|c|c|}
\hline \multirow{2}{*}{\multicolumn{2}{|c|}{ Model }} & \multicolumn{2}{|c|}{ Unstandardized Coef. } & \multirow{2}{*}{$\frac{\text { Standardized Coef. }}{\text { Beta }}$} & \multirow{2}{*}{$\mathbf{t}$} & \multirow{2}{*}{ Sig. } \\
\hline & & B & Std. Error & & & \\
\hline & (Constant) & 3.800 & 0.630 & & 6.027 & 0.000 \\
\hline & \begin{tabular}{|l|} 
College Type \\
\end{tabular} & -0.319 & 0.071 & -0.245 & -4.485 & 0.000 \\
\hline & Muslim & 0.179 & 0.634 & 0.124 & 0.282 & 0.778 \\
\hline 1 & Christian & 0.456 & 0.638 & 0.276 & 0.714 & 0.476 \\
\hline & Druze & 0.453 & 0.645 & 0.200 & 0.701 & 0.483 \\
\hline & Mixed City & 0.211 & 0.119 & 0.102 & 1.774 & 0.077 \\
\hline & Arabic Village & 0.119 & 0.075 & 0.091 & 1.595 & 0.112 \\
\hline \multirow{13}{*}{2} & (Constant) & 0.836 & 0.557 & & 1.500 & 0.134 \\
\hline & College Type & -0.229 & 0.057 & -0.176 & -3.985 & 0.000 \\
\hline & Muslim & -0.170 & 0.507 & -0.118 & -0.336 & 0.737 \\
\hline & Christian & 0.084 & 0.508 & 0.051 & 0.165 & 0.869 \\
\hline & Druze & -0.015 & 0.515 & -0.007 & -0.030 & 0.976 \\
\hline & Mixed City & 0.101 & 0.096 & 0.049 & 1.049 & 0.295 \\
\hline & Arabic Village & 0.100 & 0.060 & 0.077 & 1.669 & 0.096 \\
\hline & Hebrew Fluency & 0.006 & 0.032 & 0.008 & 0.181 & 0.857 \\
\hline & CCSE & 0.186 & 0.031 & 0.258 & 6.078 & 0.000 \\
\hline & Autonomy Support & 0.168 & 0.039 & 0.198 & 4.275 & 0.000 \\
\hline & Competence & 0.223 & 0.047 & 0.221 & 4.713 & 0.000 \\
\hline & Relatedness & 0.164 & 0.040 & 0.184 & 4.109 & 0.000 \\
\hline & Program Evaluation & 0.124 & 0.041 & 0.129 & 3.031 & 0.003 \\
\hline \multirow{19}{*}{3} & (Constant) & 1.234 & 0.607 & & 2.031 & 0.043 \\
\hline & College Type & -0.820 & 0.484 & -0.629 & -1.694 & 0.091 \\
\hline & Muslim & -0.370 & 0.500 & -0.257 & -0.740 & 0.460 \\
\hline & Christian & -0.134 & 0.504 & -0.081 & -0.267 & 0.790 \\
\hline & Druze & -0.242 & 0.509 & -0.107 & -0.475 & 0.635 \\
\hline & Mixed City & 0.088 & 0.094 & 0.042 & 0.930 & 0.353 \\
\hline & Arabic Village & 0.090 & 0.059 & 0.069 & 1.529 & 0.127 \\
\hline & Hebrew Fluency & 0.037 & 0.051 & 0.053 & 0.721 & 0.471 \\
\hline & CCSE & 0.186 & 0.047 & 0.258 & 3.939 & 0.000 \\
\hline & Autonomy Support & 0.213 & 0.055 & 0.251 & 3.858 & 0.000 \\
\hline & Competence & 0.088 & 0.066 & 0.087 & 1.338 & 0.182 \\
\hline & Relatedness & 0.077 & 0.054 & 0.086 & 1.434 & 0.153 \\
\hline & Program Evaluation & 0.250 & 0.066 & 0.261 & 3.800 & 0.000 \\
\hline & $\begin{array}{l}\text { Col. Type_Hebrew } \\
\text { Fluency }\end{array}$ & -0.041 & 0.064 & -0.132 & -0.633 & 0.527 \\
\hline & Col. Type * CCSE & 0.017 & 0.061 & 0.051 & 0.271 & 0.787 \\
\hline & $\begin{array}{l}\text { Col. Type * Autonomy } \\
\text { Support }\end{array}$ & -0.111 & 0.077 & -0.296 & -1.435 & 0.152 \\
\hline & Col. Type * Competence & 0.255 & 0.093 & 0.841 & 2.743 & 0.006 \\
\hline & Col. Type * Relatedness & 0.188 & 0.078 & 0.564 & 2.411 & 0.016 \\
\hline & $\begin{array}{l}\text { Col. Type * Program } \\
\text { Evaluation }\end{array}$ & -0.208 & 0.083 & -0.584 & -2.505 & 0.013 \\
\hline
\end{tabular}

a. Dependent Variable: LSR Autonomous Regulation (Autonomous Motivation)

Source: Author's estimations. 


\section{Summary of Hierarchical Regression Analysis for Variables Predicting Controlled Motivation $(\mathrm{N}=353)$}

In Table 5, the results of 3-step hierarchical regression, including the interaction terms between the continuous scores and college type, are presented. In step 1 (model 1), religion served as a control variable in order to account for its influence. Then, the following independent variables: Hebrew fluency, CCSE, autonomy support, competence, relatedness and program evaluation were added in step 2 (model 2). In step 3 (model 3) the interactions between college type and the independent variables were included.

Model 1 is significant: $F(4,348)=3.019, p=0.018$. Variables in model 1 improved the explanatory power of the model by an $\mathrm{R}^{2}$ change of 0.034 , resulting in an adjusted $\mathrm{R}^{2}=0.022$. Contrary to autonomous motivation model, religion was found to have a significant influence on controlled motivation. Then, the following independent variables: Hebrew fluency, CCSE, autonomy support, competence, relatedness and program evaluation were added at step 2 (model 2). Model 2 is also significant: $\mathrm{F}(10,342)=5.725, \mathrm{p}<0.0001, \mathrm{R}^{2}$ change $=0.110$, adjusted $\mathrm{R}^{2}=0.118$. Adding these variables in step 2 resulted in a model more effective in explaining the variation in students' controlled motivation. From the set of the independent variables, autonomy support and program evaluation were significant predictors of controlled motivation. Program evaluation was found to be the strongest predictor $(\beta=0.260$, $\mathrm{p}<0.0001)$, followed by autonomy support $(\beta=0.132, \mathrm{p}<0.021)$. This implies that higher levels of these two predictors are associated with higher levels of controlled motivation. However, Hebrew fluency, CCSE, competence and relatedness were not significant in predicting controlled motivation. In step 3 (model 3), the interactions between college type and the independent variables were included. Model 3, including the interactions terms, is also significant: $\mathrm{F}(16,336)=4.602, \mathrm{p}<0.0001, \mathrm{R}^{2}$ change $=0.036$, adjusted $\mathrm{R}^{2}=0.141$. Thus, the third model explained $14 \%$ of the variation in controlled motivation. The only factor significantly interacted with college type is relatedness $(\beta=0.765$, $\mathrm{p}=0.009$ ). There is a need for further investigation of the variables that could predict the Arab students controlled motivation (Table 6 \& Table 7). 
Table 6. Model Summary

\begin{tabular}{|c|c|c|c|c|c|c|c|c|c|c|}
\hline \multirow[b]{2}{*}{ Model } & \multirow[b]{2}{*}{$R$} & \multirow[b]{2}{*}{$R^{2}$} & \multirow[b]{2}{*}{$\operatorname{Adj} . R^{2}$} & \multirow{2}{*}{$\begin{array}{c}\text { Std. } \\
\text { Error of } \\
\text { the } \\
\text { Estimate }\end{array}$} & \multicolumn{5}{|c|}{ Change Statistics } & \multirow[b]{2}{*}{$\begin{array}{c}\text { Durbin- } \\
\text { Watson }\end{array}$} \\
\hline & & & & & $\begin{array}{c}R^{2} \\
\text { Change }\end{array}$ & $\begin{array}{c}F \\
\text { Change }\end{array}$ & $d f 1$ & $d f 2$ & $\begin{array}{c}\text { Sig. } F \\
\text { Change }\end{array}$ & \\
\hline 1 & $0.183^{\mathrm{a}}$ & 0.034 & 0.022 & 0.68115 & 0.034 & 3.019 & 4 & 348 & 0.018 & \\
\hline 2 & $0.379^{b}$ & 0.143 & 0.118 & 0.64687 & 0.110 & 7.310 & 6 & 342 & 0.000 & \\
\hline 3 & $0.424^{\mathrm{c}}$ & 0.180 & 0.141 & 0.63863 & 0.036 & 2.481 & 6 & 336 & 0.023 & 1.961 \\
\hline
\end{tabular}

Source: Author's estimations.

Table 7. Model Estimation Results of Controlled Motivation

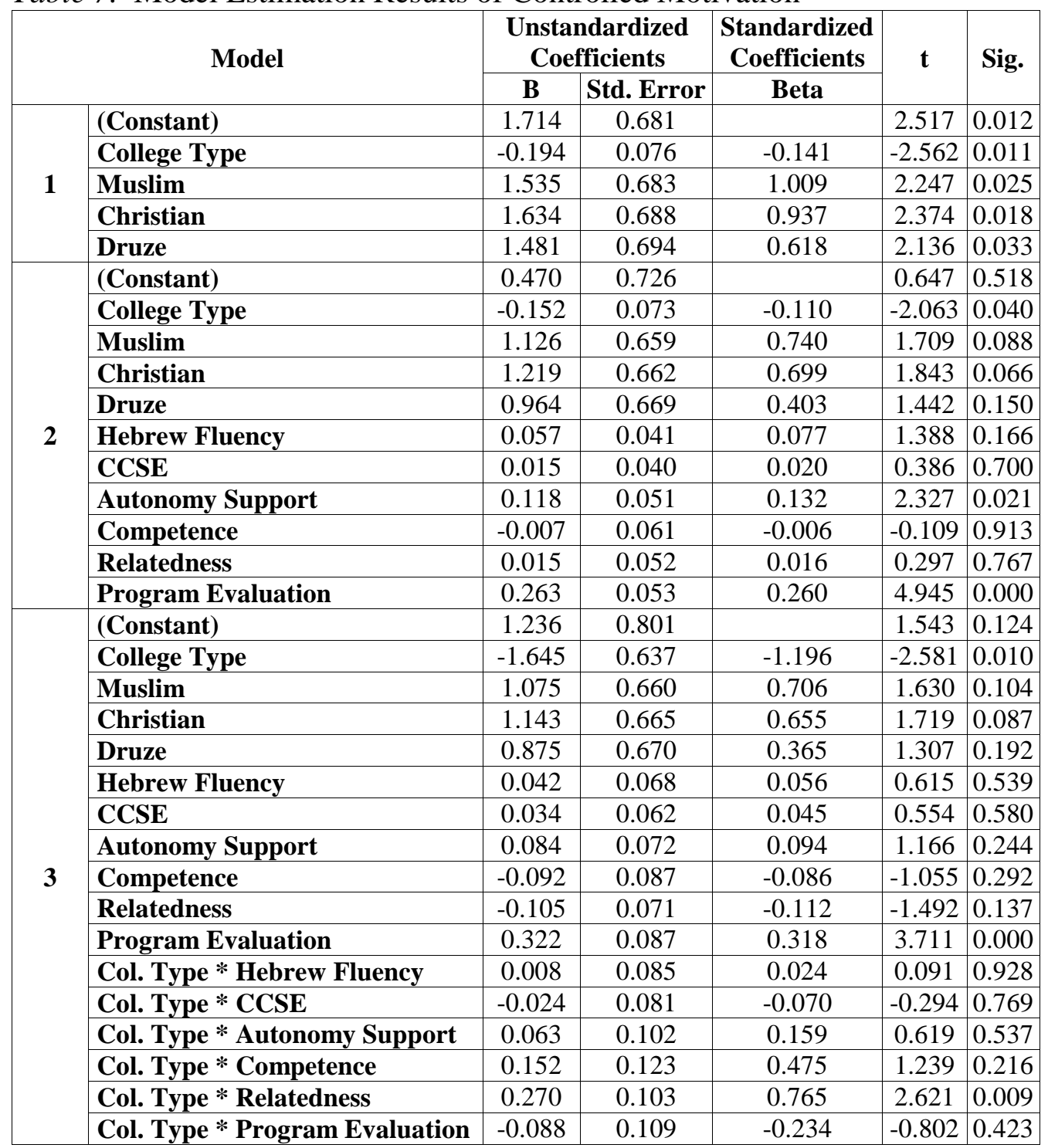

a. Dependent Variable: LSR Controlled Regulation (Controlled Motivation)

Source: Author's estimations. 


\section{Results and Discussion}

According to the present study's results, Arab students in Arab colleges have higher autonomous and controlled motivation than those in mixed colleges. Furthermore, program evaluation and autonomy support are significant in inducing both types of motivation: Students that evaluate the department programs more positively as well as students receiving higher levels of autonomy support demonstrate higher motivation.

Competence and relatedness are significant only in predicting autonomous motivation. Students with higher competence and feeling of relatedness have higher autonomous motivation. This finding is consistent with SDT theory which suggests that autonomous motives, as well as the energy and engagement they induce, are supported by contexts enhancing experiences of autonomy, competence, and relatedness (Ryan \& Deci, 2000; 2009).

CCSE is a significant predictor of autonomous motivation. Students, who chose to study Special Education freely, were found to have higher autonomous motivation. This finding further supports the concept of the interdependence between autonomy, volition and well-being.

Hebrew fluency was not found to be significant in spite of the difficulty in using second language described in the relevant literature (Shavev et al., 2013; Spolsky \& Shohamy, 1999).

College type as a moderating factor partly influenced the relationships connecting the variables of interest of the students with their autonomous motivation. According to the regression results, competence, program evaluation and relatedness had higher impacts in mixed colleges, Relatedness had higher impact in mixed colleges, and program evaluation had lower impact in mixed colleges.

College type as a moderating factor affected relatedness in controlled motivation regression model. Relatedness had higher impact in mixed colleges.

\section{Limitations}

The present study has several limitations. First, the study examined students only from four colleges, and despite its size and diversity, the testing of other colleges would allow a more comprehensive and thorough analysis. Second, the participants were selected through convenience sampling from the departments of Special Education - and therefore do not represent students in other departments. It would be interesting to conduct the research among students from other departments, and even from other colleges, in order to validate the research results. Third, the study included a small number of males, reflecting the prevalence of female students in teacher training colleges, but it could also be a limitation of research. Fourth, the study examined preservice teachers in just one point of time. Long-term testing throughout the whole duration of studies would provide more information and deliver a more 
complete image. Fifth, qualitative analysis could provide further insight on how the different factors affect both types of motivation in different colleges.

\section{Conclusion and Recommendations}

Grounded in SDT, this study tested the influence of the social and pedagogical learning context on developing motivation to learn among Arab pre-service teachers in Special Education Department. Most of the study results support the universality of the hypotheses within the SDT theoretical model (Deci \& Ryan, 2000; 2008), and provide evidence in support of this theoretical scheme across two different learning contexts. SDT theory makes an important distinction between self-determined and controlled types of motivation. It focuses not only on the quantity of motivation but also on its quality of motivation (Deci \& Ryan, 1985). In this study, the three psychological needs were found to explain the autonomous type of motivation, a result consistent with the findings of the majority of related studies (Assor \& Kaplan, 2001; Assor et al., 2002; Connell et al., 1994; Deci et al., 1996; Flink et al., 1990; Grolnick \& Ryan, 1987; Kaplan, et al., 200, as cited in Katz \& Assor, 2006; Grolnick, Ryan \& Deci, 1991; Skinner \& Belmont, 1993). However, autonomy support was also found to induce controlled motivation, a finding which contradicts the relevant studies in the field of SDT, which emphasize that autonomy supportive climates are expected to enhance autonomous motivation and decrease controlled motivation. This can be partly explained on the basis of the Arab collectivist society, in which some individual choices are influenced by society expectations and culture. SDT embraces the idea that cultures do influence people in important ways but it is based on the consideration that all individuals have certain psychological needs that need to get satisfied in order to experience optimal well-being, with those needs being independent of the cultural context (Deci \& Ryan, 2008). Recently, a debate has risen regarding the cross-cultural validity of this theory, with some scholars arguing that the psychological needs are culture-bound and others arguing that the psychological needs generalize across cultures. Moreover, the cultural context within which the students evolve and behave may affect their answers to the questionnaires. It could also be possible that people in some cultures have higher total motivation than people in other cultures.

Students' evaluation of the Special Education program they attend explains the two types of motivation. Consequently, the students' perceptions and evaluations of the program they attend are of great importance when it comes to the formation of their motivation to learn. Students who rated their program high in the ranking scale had higher levels of both autonomous and controlled motivation. In addition, students' choices were found to predict autonomous motivation. Students who had chosen the college type and Special Education Department freely were more autonomously motivated. This finding also comes in agreement with results of previous studies (Katz \& Assor, 2006). 
Students who are asked to fill out questionnaires so far tend to give quick and not always adequate answers while some of them even tend to respond according to what they think the researcher would expect. Therefore, social desirability bias, existing among Arab participants in Arab society (Zeidner, 1992), could pose a further limitation to the present study, since the mean answers in both college types were of higher quality than the expected and had been previously observed in the field. There seems to be a gap between what is observed in the field and what the students are trying to show through their responses to the questionnaires. One way to avoid such a bias in future research is to construct a measure of social desirability such as the one designed by Delroy L. Paulhus (Paulhus, 1991) Balanced Inventory of Desirable Responding (BIDR).

The current research does not support the argument of the comparative efficiency of Arab vs. mixed approaches to college education in terms of achieved levels of knowledge, competence and future success within the Special Education field. The research results should not be interpreted in terms of identifying one single college type as preferred compared to other types, but they should be approached as an examination for those parameters that could be used to improve both learning contexts. A significant difference was found between the two types of colleges, but the means are very close. Means of predictor variables, and outcome variables were all higher in Arab colleges. Students in Arab colleges had higher levels of motivation (quantity) and higher in both motivation types. Arab students in mixed colleges seemed to pay the price of increased feelings of pressure and lower feelings of autonomy.

Consistent with prior research, the findings of the present study highlights the potential importance of the need for psychological needs support across different learning contexts and settings, and specifically in the case of Arab pre-service teachers. Such results add to a growing body of literature, which suggests that the need for autonomy, competence, and relatedness are crossculturally significant needs common in various learning environments (Jarjoura, 2015; Ryan \& Deci, 2000). Although there may be cultural and institutional differences on how the psychological needs are supported, fulfilled, and expressed, the importance of experiencing satisfaction of these needs seems to be essential for the improvement of students' growth and wellbeing. An ideal education system would support both students' choice and competence and work in the direction of inspiring senses of belonging, autonomy and self-regulation.

Students' autonomy should be taken into consideration when choosing efficient strategies for motivating them to learn and achieve high performance, such as sharing enthusiasm for the subject and making the learning materials more appealing to the students. Showing patience, persistence and understanding with students' various difficulties could moderate and reduce the students' resistance in dealing with their own difficulties.

These results can be proven crucial to the pedagogical supervisors and policy makers for designing guidelines that enhance students' learning abilities, such as intervention programs operating in parallel circles. Other ideas for 
effective policy guidelines could be the development of programs and support systems for new students in particular and workshops aimed to help students to deal with the challenges they face especially in mixed colleges. Development of workshops for lecturers and pedagogical supervisors could also serve the same purpose by making the teachers more student-oriented, more accessible to students and responsive to their needs and concerns.

Finally, it should be noted that the study raises the question of multiculturalism, putting in the center of attention the process that college needs to undergo in order to adapt to different cultures. In order to provide the Arab minority with the essential tools to deal with the complex reality of their cultural and national uniqueness in Israel, it is important to start from an early stage by implementing multicultural policies at all educational levels.

\section{References}

Abu-Baker, K. \& Dwairy, M. (2003). Cultural norms versus state law in treating incest: A suggested model for Arab families. Child Abuse and Neglect, 27, 109123.

Abu-Rabia, S. (1999). Towards a Second-language Model of Learning in Problematic Social Contexts: the case of Arabs learning Hebrew in Israel. Race Ethnicity and Education, 2(1), 109-126.

Agbaria, A. (2009). Rehabilitation policies in the Arab Teachers College in Israel and identity entitlements. Al- Karma 6, 9-33. Jerusalem: David Yellin Academic College [In Arabic].

Agbaria, A. (2010). Arab Teacher Training in Israel: Overview and Policy Recommendations. Dirasat, Nazareth [In Arabic].

Al-Haj, M. (1989). Social research on family lifestyle among Arabs in Israel. Journal of Comparative Family Studies, 20(2), 175-195.

Al-Haj, M. (1996). Education among Arabs in Israel. Control and Social Change. Jerusalem: Magnes [In Hebrew].

Al-Haj, M. (2002). Adjustment problems of Arab and Jew students in Haifa University. Tracking Survey. Multiculturalism Center: University of Haifa [In Hebrew].

Bandura, A. (1989). Human agency in social cognitive theory, American Psychologist 44(2), 75-84.

Ben-Raphael, A. (2002). Multicultural and Multilingual in Israel. In Sh' Israel (Ed.), Speaking Hebrew: Research in spoken language and various linguistic in Israel (pp. 67-84). Tel-Aviv: Tel-Aviv University [In Hebrew].

Connell, J. P. \& Wellborn, J. G. (1990). Competence, autonomy and relatedness: A motivational analysis of self-system processes. In M. Gunnar \& A. Sroufe (Ed.), Minnesota symposium on child psychology 23 (pp. 43-77). Hillsdale, NJ: Lawrence Erlbaum Associates, Inc.

Daas, R. (2013). Arab teacher training special education: an alternative perspective. In A. Agabaria (Ed.), Teacher Education in the Palestinian Society in Israel Institutional Practices and Education Policy. (pp. 127-145). Israel: Resling publishing, [In Hebrew].

Deci, E. L. \& Ryan, R. M. (1985). Intrinsic Motivation and Self-Determination in 
Human Behavior. New York: Plenum Press.

Deci, E.L. \& Ryan, R.M. (2000). The "what" and "why" of goal pursuits: Human needs and the self-determination of behavior. Psychological Inquiry, 11, 227-268.

Deci, E.L. \& Ryan, R.M. (2008). Facilitating optimal motivation and psychological well-being across life's domains. Canadian Psychology, 49, 14-23.

Deci, E. L., Vallerand, R. J., Pelletier, L. G. \& Ryan, R. M. (1991). Motivation and education: The self-determination perspective. Educational psychologist, 26(3-4), 325-346.

Diab, K. \& Daas, R. (2013). The Arab education and learning system in Israel: Persistent gaps in the shadow of demand for social equality. El-Karma, (8-9), $7-$ 43 [In Arabic].

Dwairy, M. (1998). Cross cultural psychotherapy: The Arab Palestinian case. New York: Haworth Press.

Dwairy, M. (2001). Foundations of psychological dynamic personality theory of collective people. Clinical Psychology Review 22, 343-360.

Eccles, J. S. \& Wigfield, A. (2002). Motivational beliefs, values, and goals. Annual review of psychology, 53(1), 109-132.

Filak,V.F. \& Sheldon, K.M. (2003). Student psychological need satisfaction and college teacher- course evaluation. Educational Psychology, 23 (3), 235-247.

Fortier, M. S., Vallerand, R. J. \& Guay, F. (1995). Academic motivation and school performance: Toward a structural model. Contemporary educational psychology, 20(3), 257-274.

Grolnick, W. S., Ryan, R. M. \& Deci, E. L. (1991). Inner resources for school achievement: Motivational mediators of children's perceptions of their parents. Journal of Educational Psychology, 83, 508-517.

Haidar, A. (2005). The book of Arab society in Israel: population, society, economy. Jerusalem: Van ler institute, KM publisher.

Haj-Yahia, M. M. (1995). Toward culturally sensitive intervention with Arab families in Israel. Contemporary Family Therapy, 17(4), 429-447.

Haj-Yahia, M., Bargal, D. \& Guterman, N. (2000). Perception of job satisfaction services effectiveness and burnout among Arab social workers in Israel. International Journal of Social Welfare, 9, 201-210.

Hofstede, G. \& McCare, R. (2004). Personality and Culture revisited: Linking traits and dimensions of Culture. Cross-Cultural Research, 38, 52-88.

Ilaiyan, S., Zedan, R. \& Torin, Z. (2007). Motives in choosing the teaching profession among Arab teaching students. Dapeem, 44, 123-147 [In Hebrew].

Jarjoura, B. (2015). Developing Motivation to Learn Among Arab Students in Arab Colleges and Mixed Colleges. ATINER's Conference Paper Series, No: HUM2015-1373. Athens: ATINER.

Katz, I., \& Assor, A. (2006). When choice motivates and when it does not. Educational Psychology Review, 19(4), 429-442.

Kim, H. \& Cho, Y., (2014). Pre-service teachers' motivation, sense of teaching efficacy, and expectation of reality shock. Asia-Pacific Journal of Teacher Education, 42(1), 67-81.

Niemiec, C. P. \& Ryan, R. M., (2009). Autonomy, competence, and relatedness in the classroom Applying self-determination theory to educational practice. Theory and Research in Education, 7(2), 133-144.

Paulhus, D. L., (1991). Measurement and control of response bias. In J.P. Robinson et al. (Ed.), Measures of personality and social psychological attitudes. San Diego: Academic Press. 
Peleg, R. \& Raslan, Sh. (2003). The evaluation of teacher training of minorities in Oranim College: multiculturalism model or uniform. Tivon: Oranim College [In Hebrew].

Pintrich, P. R. \& Zusho, A., (2007). Student motivation and self-regulated learning in the college classroom. In P.P. Raymond \& J. C. Smart (Ed.), The scholarship of teaching and learning in higher education: An evidence-based perspective. (pp. 731-810) Netherlands: Springer.

Raingold, R. \& Paul, E., (2013). Separate teacher training to Arab academies students in state education teacher training: multi -cultural based dialogue. In A. Agabaria (Ed.), Teacher Education in the Palestinian Society in Israel -Institutional Practices and Education Policy, 2013. (pp. 275-292). Israel: Resling publishing, [In Hebrew].

Ryan, R. M. \& Deci, E. L., (2000). Self-determination theory and the facilitation of intrinsic motivation, social development, and well-being. American Psychologist 55(1), 68-78.

Ryan, R.M. \& Deci, E.L., (2009). Promoting self- determined school engagement: Motivation, learning and well- being. In K.R. Wentzel \& A. Wigfield (Ed.), Handbook of motivation in school (pp. 171-196). New York: Routledge.

Ryan, R.M. \&Weinstein, N., (2009). Undermining quality teaching and learning- A self-determination theory perspective on high-stakes testing. Theory and research in education, 7(2), 224-233.

Schunk, .H., Pintrich, P.R. \& Meece,J.L., (2008). Motivation in Education. Theory, Research, and Applications. Pearson: Merrill Prentice Hall.

Shavev, M., Benshtain, N., Ston, A., Poden, A., (2013). Pluralism and equal opportunity in higher education- Expanding Arab, Druze and cherkessians access to Academy in Israel. Professional staff report of Planning \& Budgeting Committee, Council for higher education [In Hebrew].

Skinner, E. A., \& Belmont, M. J., (1993). Motivation in the classroom: Reciprocal effects of teacher behavior and student engagement across the school year. Journal of educational psychology, 85(4), 571.

Skinner, E. A., Wellborn, J. G. \& Connell, J. P., (1990). What it takes to do well in school and whether I've got it: A process model of perceived control and children's engagement and achievement in school. Journal of educational psychology, 82(1), 22-32.

Spolsky, B., \& Shohamy, E. G., (1999). The languages of Israel: Policy, ideology, and practice, Multilingual Matters, 17.

Vallerand, R. J. \& Bissonnette, R., (1992). Intrinsic, extrinsic, and amotivational styles as predictors of behavior: A prospective study. Journal of Personality, 60, 599620.

Vallerand, R. J., Fortier, M. S. \& Guay, F. (1997). Self-determination and persistence in a real-life setting: Toward a motivational model of high school dropout. Journal of Personality and Social psychology, 72, 1161-1176.

Wigfield, A., Cambria, J. \& Eccles, J.S. (2012). Motivation in education. In R.M. Ryan (Eds.), The Oxford handbook of human motivation (pp. 463-478). Oxford university press, Inc.

Williams, G. C., Minicucci, D. S., Kouides, R. W., Levesque, C. S., Chirkov, V. I., Ryan, R. M., \& Deci, E. L., (2002). Self-determination, smoking, diet and health. Health education research, 17(5), 512-521.

Ying, Y. W., Lee, P. A., Tsai, J. L., Hung, Y., Lin, M., \& Wan, C. T. (2001). Asian 
Vol. 2, No. $4 \quad$ Jarjoura: Developing Motivation to Learn among Arab Students...

American college students as model minorities: An examination of their overall competence. Cultural Diversity and Ethnic Minority Psychology, 7(1), 59.

Zeidner, M., (1992). Sources of academic stress: the case of first year Jewish and Arab college students in Israel. Higher Education, 24(1), 25-40. 